\title{
No inheritance data available
}

INSERM

\section{Source}

INSERM. (1999). Orphanet: an online rare disease and orphan drug data base. no

inheritance data available. ORPHA:409940

No information is available in the scientific literature on heredity of the clinical entity. 